\title{
An Analysis of the Optimal Allocation of Core Human Resources in Family Enterprises Based on the Markov Model
}

\author{
Jinyang Cao \\ Faculty of Social Sciences and Humanities, Universiti Teknologi Malaysia, 81310 UTM Johor Bahru, Joho, Malaysia \\ Correspondence should be addressed to Jinyang Cao; caojinyang1994@st.btbu.edu.cn
}

Received 17 November 2021; Accepted 23 December 2021; Published 17 January 2022

Academic Editor: Miaochao Chen

Copyright (c 2022 Jinyang Cao. This is an open access article distributed under the Creative Commons Attribution License, which permits unrestricted use, distribution, and reproduction in any medium, provided the original work is properly cited.

\begin{abstract}
As an important component of family business management, human resource allocation greatly affects all aspects of the company's strategic direction and organizational structure. Therefore, the optimal allocation of core human resources in family businesses has become a topic of great practical significance. Based on the Markov model, this article is based on the B/S architecture, designed the three-tier architecture of the presentation layer, business logic layer, and data layer adopted by the system, forming the basis of quality management, job management, performance management, and salary management-oriented human resources optimization configuration system. Taking family business A as an example, the Markov chain is used to predict the flow of personnel in the company in the next three years. The results show that with the development of normalization and the improvement of the management level, the demand for personnel in the family business will decrease year by year. Competency analysis of human resources positions found that grassroots employees have higher requirements for competency, but at the same time, lower performance requirements, while company seniors need relatively low requirements for competence indicators and higher requirements for performance. In addition, through data calculation and prediction, it is found that the prediction accuracy of the model algorithm is $81.37 \%$ on average. Compared with other model algorithms, the Markov model algorithm has the highest accuracy in predicting the state, and the accurate prediction results make the recruitment work predictable. The system makes up for the shortcomings of traditional human resource management data, such as insufficient data, low accuracy, and inability to achieve homogeneity. It uses a centralized database to comprehensively and organically link human resource management-related information to provide a basis for future family business human resource optimization.
\end{abstract}

\section{Introduction}

The so-called family business, "is based on blood relationship, with family interests as the goal, assets, shares, and management rights are mainly controlled in the hands of a family, and family members hold major leadership positions" [1]. With the adjustment of the industrial structure and the slowdown of economic growth worldwide, the market environment and the overall competitive situation faced by enterprises have undergone certain changes, and family businesses are facing greater pressure and challenges. From a global perspective, the average life span of family businesses is relatively low: "In the United States, two-thirds of companies in each industry have a life span of no more than 6 years; in Japan and Europe, the average life span of all large and small companies is only 12.5 years; and the lifespan of family businesses in the new era in my country is even shorter, with an average lifespan of only 2.9 years [2]." The problems of human resource management in family businesses are an important reason for the short lifespan of family businesses. There are four main reasons: irrespective of family business, arbitrary behavior; nepotism to exclude dissidents, lack of talents; extensive management efficiency and lack of system; incentive mechanisms are useless. There is a difference between inside and outside. If family businesses want to survive and develop, they must conform to economic development trends, change concepts, innovate, and seek new economic growth points. Innovation not only refers to technological innovation but also to human innovation. The core human resource system with people as the management goal must be continuously optimized. This is the foundation for ensuring that family businesses remain 
invincible in the fierce market competition. It is also the key factor for the success of modern enterprises [3]. Therefore, the research on the optimal allocation of human resources in family businesses has an important theoretical value and practical significance.

In the 1950s, the concept of "human resources" was born. The sum of the labour abilities possessed by all people in a specific scope is human resources, which includes human intelligence, physical strength, knowledge, skills, and so on. Intelligence refers to the ability of a person to recognize and understand objective things and the ability to use knowledge and experience to solve problems; physical strength refers to the functional state of the human body and the ability to transform objective things; knowledge refers to the experience that people gain from living in the objective world; skills refer to the habitual actions formed by the knowledge and abilities that people have acquired through personal and objective activities. In order to make their human resources superior and thus carry out efficient production and operation activities, a series of actions are taken to the enterprise's human resources. The reasonable allocation measure is the allocation of human resources [4]. In addition, enterprises or organizations combine existing human resources with other production factors, and such related activities also belong to human resource allocation [5]. Therefore, the allocation of human resources should be based on the job setting of the enterprise or organization, selecting and using suitable talents, matching the positions, and making the best use of their talents. Because of the imperfect human resource allocation system of family business, the development of the business is limited and the life span is short. To realize the optimal allocation of human resources, it must not only meet individual needs but also meet the overall development needs. The allocation of human resources requires that each employee's individual job position and its functions adapt to each other in order to reflect the responsibilities of the position and enable him the ability to be displayed in their appropriate positions which can ensure that employees are responsible for their positions and behaviours and complete the assigned tasks with high efficiency and high quality. In the process of resource allocation, the manager of the organization should provide individual members with a broad space for personal development, fully explore the individual potential of the individual in the organization, and while meeting the normal operation and development goals of the organization, they must also take into account the realization of individual employees' personal values, and then, ensure the quality of work and work efficiency. Organization members should also conduct necessary communication from time to time to ensure the adequate configuration and application of organizational human resources. When assigning personnel, it is necessary to start from the macroview of the organization, analyze the needs of the organization and the needs of individuals within the organization, and design a human resource allocation system based on the needs of both, so that the system can be implemented more efficiently.

Commonly used forecasting models include gray forecasting, neural network forecasting, and Markov model. The
Markov model is a dynamic forecasting model with higher accuracy in human resource forecasting. Markov prediction is based on the random process theory of the Russian mathematician AA Markov. It uses the transition probability matrix between states to predict the state of events and their development trends. It is a time series analysis method for studying random processes. Prediction technology of development and change laws [6]. Since it was first proposed at the beginning of the 20th century, it has developed more maturely and has been applied to various fields. At present, the Markov model has become a very important quantitative analysis technology in human resource forecasting. It can discover the rules of corporate personnel changes and provide a more accurate basis for the reasonable allocation of current corporate human resources. However, most people usually regard irregularly changing data as interference data during the actual model establishment process. The main purpose is to show the overall trend of changes more clearly during the forecasting process and use it to predict future data. However, this method of eliminating interfering data often produces errors, which leads to a decrease in the overall accuracy of the prediction model. How to overcome the shortcomings of the prediction model and further improve the prediction accuracy of the model has become the focus of scholars' research.

This article aims to use the Markov model's advantages in human resource supply and demand forecasting, relying on the massive storage and processing capabilities of the system, to quantitatively study the distribution of family business personnel and to predict the distribution of various types of family business personnel. In the future, we will realize the optimal allocation of family business positions and positions matching and making the best use of their talents.

\section{Related Work}

In the new situation where the reform of family businesses is intensified, companies are accelerating the pace of human resource reform. Through the practice of optimizing the allocation of human resources, the company realizes a reasonable total number of employees and a complete technical force and builds a qualified workforce in all aspects, thereby improving the quality of enterprise human resources management, driving the improvement of the enterprise management level, and enhancing the overall competitiveness of the enterprise. Tadayon et al. researched and selected the competency model as the main research method, deeply analyzed the structure of the competency model, combined with the enterprise's human resource allocation, with the work competency index model, and with the needs of the enterprise, proposed the optimization of modern new human resource allocation program, and studied the role and applicability of the competency model for the optimization of human resource allocation in the enterprise service industry [7]. Monaco et al. studied and analyzed the problems in the allocation of human resources. The tools were the analytic hierarchy process and linear programming and used several cases to prove that the two 
methods can be superimposed to effectively solve the problem of allocation of human resources. It proposed a multilevel decision-making model, which is based on a multiobjective hybrid genetic algorithm. This model can be used to solve the problem of multistandard combination and multilevel combination of human resources optimization configuration [8]. Ballesteros-Perez et al. constructed a multiskilled human resource allocation model, which uses the concept of fuzzy numbers to calculate the threshold [9]. Ayesta et al. used the gap analysis framework as a tool to find out the gaps in human resource allocation in California school districts. After literature analysis and comparison, qualitative research uses formative evaluation methods to simulate the practice of manpower allocation [10]. Witteveen et al. used the genetic algorithm (GA) to solve the problem of human resource allocation. The evaluation results show that the genetic algorithm can solve practical application problems by minimizing personnel's multitasking time, continuous assignment of related tasks, and configuration balance [11]. Duan et al. used the ordinary least squares method and analytic hierarchy process to analyze the human resource allocation of customs and formulated corresponding measures to optimize the allocation of customs human resources from both macro and microaspects [12]. Karikari et al. used the genetic algorithm to construct a multiobjective hybrid genetic algorithm model and verified through a case that the model can effectively solve the problem of human resource allocation. The model mainly uses the basic characteristics of the genetic algorithm multidirectional and global search, mostly used to study the problem of multistage human resource allocation [13]. Vu established a theoretical framework model of human resource big data management, which mainly involves three levels, namely, human analysis, human resource management department, and organization [14]. Many scholars have conducted research on different models. The Markov model algorithm is the most commonly used algorithm. This method follows the principle of inertia, that is, learning from the past and knowing a certain thing.

With the rapid development of modern society and economy and the continuous optimization of various systems of modern enterprises, human resources have also shown more and more important significance and influence on the survival and development of an enterprise. With the continuous development and advancement of intellectual property rights and social economy, the good effect of rational allocation of human resources on the development of enterprises has become more and more significant. The enterprise allocates human resources scientifically and rationally to form a good mechanism for human resources management, which can urge enterprise human resources to show better work performance, and can improve the organizational efficiency and overall work efficiency of the enterprise [15]. Therefore, enterprise managers and human resources workers should pay more attention to the allocation of enterprise human resources. As the market environment grabs human resources and competition becomes more fierce, scientific, effective, and reasonable allocation of human resources can enable enterprises to play an important role in both short-term benefits and long-term development in the face of fierce market competition. Rafiei et al. conducted research on the importance of human resource management, proved the important contribution of human resource management practice to organizational goals from multiple angles, and used strategic and management methods to evaluate the importance of human resource management [16]. According to the competency model, Vaish et al. put forward many problems in the recruitment process. According to the competency model, the recruitment process should focus on examining whether the applicant has the ability to hold the position. However, the recruitment of enterprises is mostly limited to linking the ability to hold the job with high education and deep qualifications, the objectivity of recruitment [17]. Wang et al. pointed out that the optimization and improvement of the rational allocation of human resources is particularly important for the development of enterprises, especially the ability to optimize the allocation of employees under limited resource conditions, which is essential to improve the efficiency of the enterprise. This research confirms the importance of reasonable allocation of human resources and at the same time puts forward reasonable suggestions for enterprise talent optimization [18]. Luddin et al. proposed a configuration model that can be applied to a large-scale production supply chain enterprise from the perspective of cost. In the case of limited labour conditions, employees in key business positions can be prioritized to make full use of existing resources to ensure that the organization achieves maximum efficiency operation [19]. This model can maximize to help companies reduce operating costs in a crisis environment and provide another feasible solution for the practice of human resource allocation in the company.

According to the research and discussion of many Chinese and foreign scholars, combined with the current low staffing rate and mismatch of human resources in the current family business, how to predict the human resource allocation, match the human resources of the family business as much as possible, and make the best use of their talents has become the focus of scholars' research. At present, the majority of family businesses are facing urgent challenges and problems that need to be resolved.

\subsection{The Allocation System of Core Human Resources in Family} Enterprises Based on the Markov Model. At present, many family businesses have formally applied the human resource management system to carry out corresponding work. However, most of the systems are of general-purpose type, purchased directly through the market, and their functions are too single, unable to meet the individual business needs of the human resources department of the enterprise, and cannot match the rapid development of the enterprise, resulting in many businesses that cannot be effectively processed. Some family enterprises have low system utilization and complicated system operations, which are not suitable for enterprises. Therefore, in view of the various problems of the current general system, it is necessary to construct a family business human resource optimization 
configuration system according to the different needs of the family business.

Starting from the application requirements of the family business, this chapter uses the three-tier system architecture flexibly in accordance with the overall design tasks of the system logic architecture, functional architecture, and network topology to achieve a reasonable division of system functional modules.

\subsection{Family Business Human Resource System Architecture.} The family business human resource system architecture is mainly based on the relevant system design principles. All modules of the system are scientifically organized at all levels to obtain a large number of structures related to the system and finally form the required architecture. The so-called human resource architecture design is to complete the overall to partial division of a system from the macrolevel [20]. With the help of logical architecture, it is possible to determine which logical elements are included in the system and the connections between them. The focus is on functions, covering two types of functional modules that are visible and implicit in the system. Under normal circumstances, people tend to choose the typical "layered" design concept, divide the family business human resource system into 3 or more levels, and then optimize the configuration and deployment of all modules. The logical architecture of this system is based on a three-tier architecture based on $\mathrm{B} / \mathrm{S}$, relying on the MVC model, following the object-oriented design ideas, using the SSH framework and introducing mainstream design models to build. Combining the requirements of system functions, three levels are reasonably divided, and through the effective coordination of functions of each level, various business processes of the family business can be realized, as shown in Figure 1.

2.2.1. Presentation Layer. The main function of the presentation layer is to provide a good user interface for family business users, involving user information input, information display, and notification message prompts [21]. This system mainly uses HTML to display the page and uses the browser to show the interaction between the client and the server.

2.2.2. Business Logic Layer. The business logic layer is the core layer of the system, in which almost all functions involved in the family business human resource management system are logically processed, receiving user requests and instructions, and process these requests according to the specific access of the system content, encapsulate database access and abstract data, and create corresponding interfaces. According to different requests, different view methods are processed logically, and the corresponding interactive interface is generated to return the result.

2.2.3. Data Layer. The main function is to access the database of the family business human resource system. When the business logic layer needs to access the data table, it will send a query request to this layer, and the database access layer will operate on the corresponding data table according to this request. Pass the result back to the business logic layer. At the same time, in the database, different data table structures are constructed under unused business functions, and the data are classified and stored to improve the efficiency of the human resource system.

2.3. Family Business Human Resource System Function. The functional design of the human resources system of the family business focuses on the effective refinement of the core functions of the system and the realization of the structure organization according to the functional subordination. Through the comprehensive understanding and familiarization of the system architecture, the key functional requirements of the family business system users are converted into technical requirements, and the corresponding functional architecture is clearly defined, as shown in Figure 2.

Combining the above figure to explain, the family business human resource system fully introduces the modular architecture design concept, based on the actual functional requirements of the system, completes effective differentiation for all functions, and at the same time follows the subordination relationship to achieve a scientific and standardized organization. From the perspective of the toplevel structure, the system is subdivided into five subsystems, which provide corresponding functional operations to jointly implement various business processes, improve business processing efficiency, and allow users to obtain good services. First, the personnel management module, which mainly serves the users of personnel specialists, can perform operations such as adding/deleting/modifying/ checking basic employee information according to needs and can solve management needs such as employee transfer and contract information. The second is the organization management module, which mainly serves organization specialist users. It can initiate organization unit and postinformation addition/modification/checking services as needed, and it can manage the overall organization framework of the enterprise accordingly. The third is the recruitment management module, which mainly serves recruiter users and can be used for high-efficiency management of the entire recruitment process according to the needs of the recruitment needs until the personnel are hired. Fourth, the training management module mainly serves training specialist users and can manage training needs and results as needed. According to the different positions and work content of the employees, the human resources department should organize and carry out different levels of training forms according to local conditions and evaluate the training results. Fifth, the salary management module mainly serves the users of salary specialists, which can calculate the salary of employees and accurately record the salary of different employees. In addition, the system also provides some general management functions, such as user, authority, and log management. All functions interact with each other and are processed jointly to form a complete 

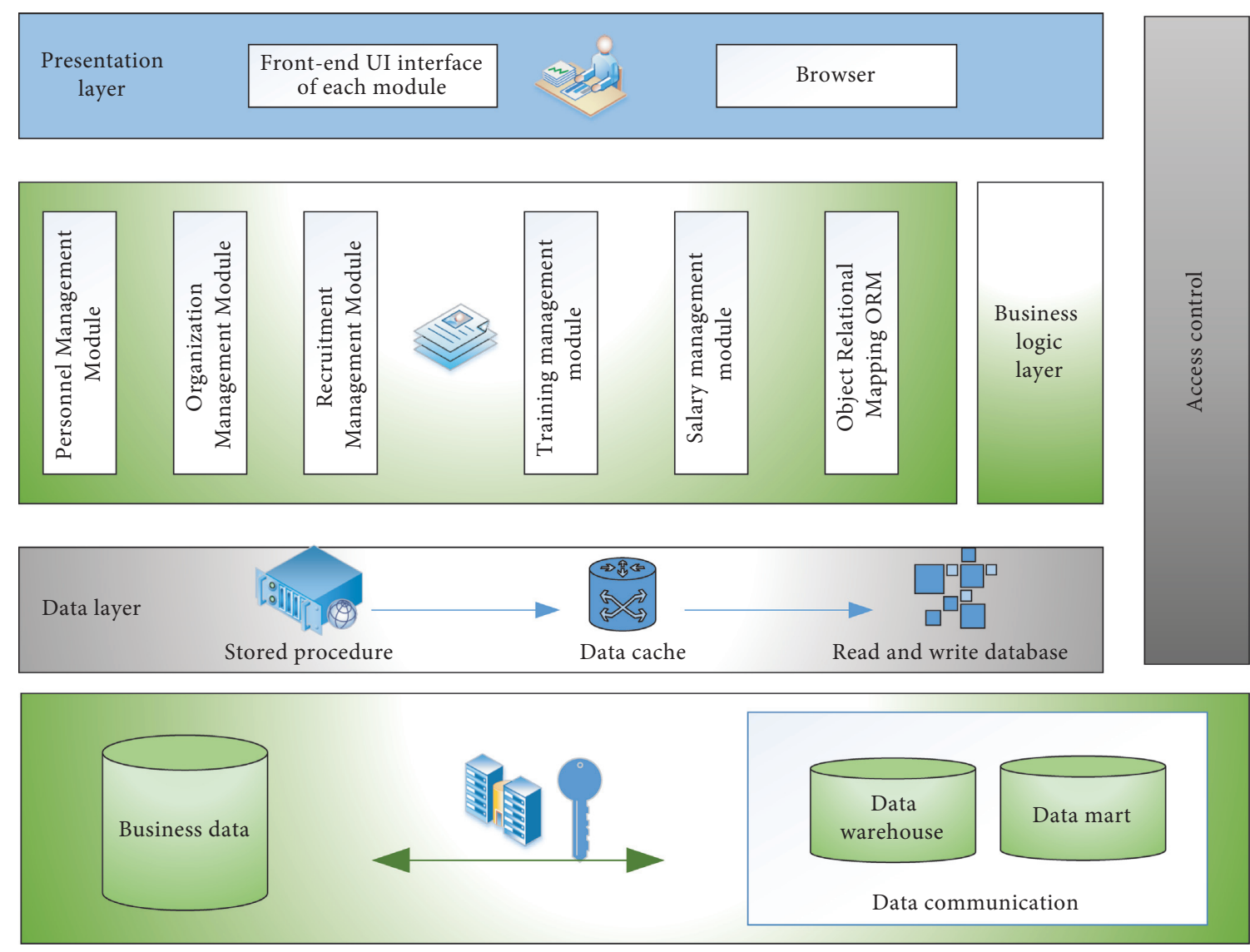

Figure 1: Human resource system architecture diagram.

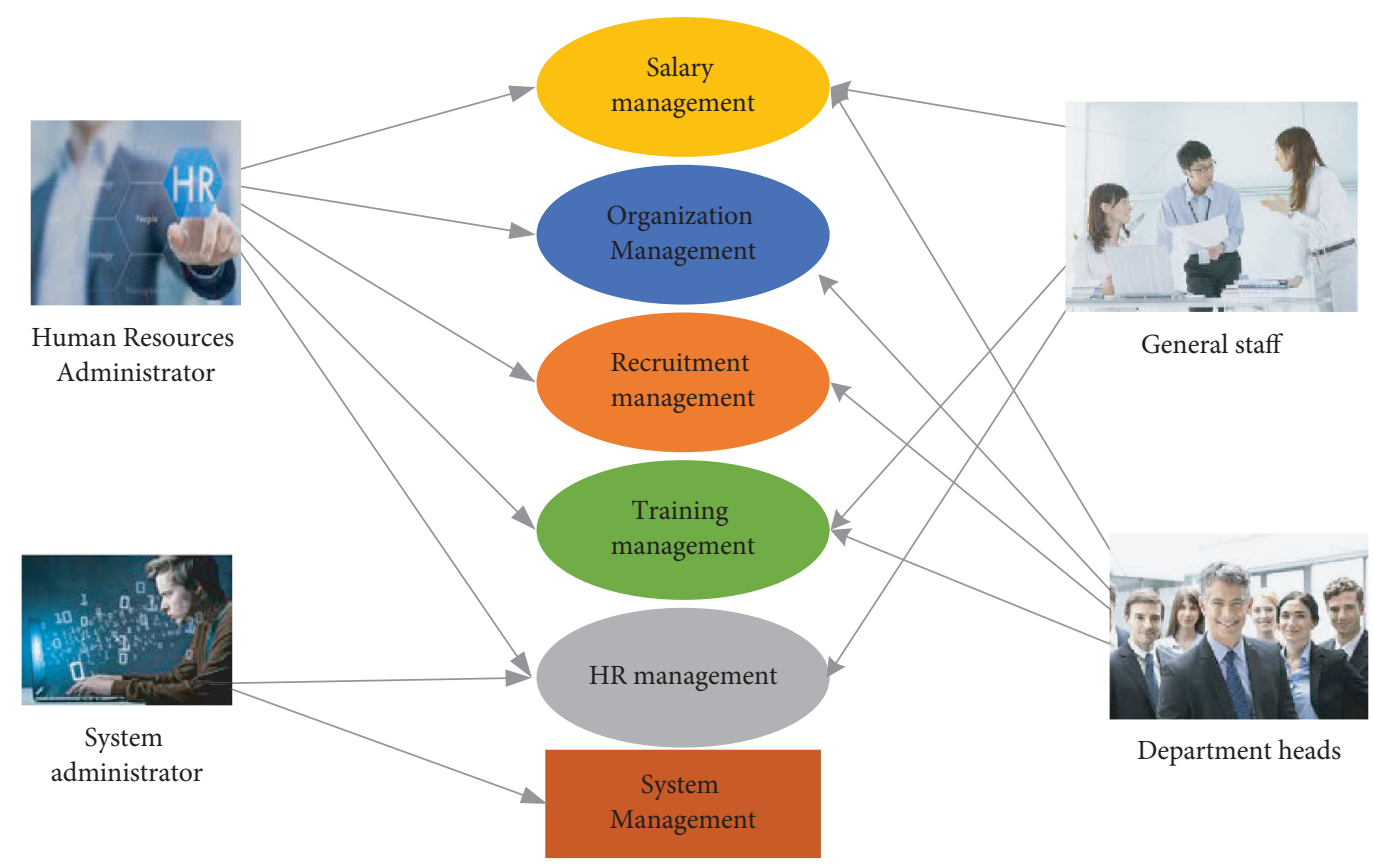

FIgURE 2: Human resource system function diagram. 
system, which truly solves the actual needs of various users of the family business.

2.4. Network Topology Design. The network topology structure diagram of the family business human resource system is shown in Figure 3. The system uses the B/S architecture. The user needs to connect to the system through the network and exchange routes through the Internet to maintain the connection. The main constraint protocol involved is the HTTP protocol. The server is mainly composed of two parts, namely, the web server and the database server. The web server mainly deals with the corresponding business process, and the web server can directly access the database server. The internal nodes of the company include all computers connected to the intranet. The user can access the system through any of these computers. Because in some special cases, an access mechanism is also provided for external users who are not connected to the company's intranet, and users can access through VPN communication, and ensure the security of data information through the firewall set by the company.

In summary, this chapter focuses on the status quo and development needs of family businesses and develops a convenient, efficient, safe, stable, and feasible human resource optimal allocation system based on the B/S three-tier system architecture, which addresses the optimal allocation of family business human resources. Analysis and research play an important role.

\section{Realization and Problem Analysis of Human Resource Optimization Allocation Forecast}

Based on the important predictive role of the Markov model in the human resource system of the family business, this chapter uses the Markov model to analyze the distribution of enterprise personnel flow, the realization of job allocation, the quality of job competence, and the accuracy of the system model.

\subsection{Markov Model and Prediction Steps}

3.1.1. Markov Model Definition. The Markov model refers to a time series with no after-effect, that is, the state of the sequence in the future is only related to its current state and has nothing to do with its past state. No after-effect can be expressed by conditional probability.

Definition 1. Suppose the state space $S$ of the time series $Z_{t}$ is an integer set, if for any $m$ integers in $S: i, j, i_{1}, \ldots, i_{m-2}$, any $m$ integers in $i_{m-2}$, and $T\left(0 \leq t_{1}<t_{2}<\ldots t_{\mathrm{m}}\right)$ have [22]

$q\left\{z_{t_{m}}=j \mid z_{t_{1}}=i_{1}, z_{2_{1}}=i_{2}, \cdots, z_{t_{m-1}}=i\right\}=p\left\{z_{t_{m}}=j \mid z_{t_{m-1}}=i\right\}$

Then, call the time series $Z_{\mathrm{t}}, t \in T$ is a Markov chain. Conditional probability is

$$
q\left\{z_{t m}=j \mid z_{t_{m-1}}=i\right\}
$$

Call the state transition probability from state $i$ at time $t_{\mathrm{m}-1}$ to state $j$ at time $t_{\mathrm{m}}$, denoted as

$$
q_{i j}\left(t_{m-1}, t m\right)
$$

Definition 2. Suppose the state space of Markov chain $Z_{t}$, $t \in T$ is $S=\{1,2, \ldots, \mathrm{m}\}$; then, it is said to be composed of onestep transition $q_{i j}(i, j=1,2, \ldots, m) m$-order square matrix [23]:

$$
q=\left(q_{i j}\right)_{m \times m}=\left(\begin{array}{ccc}
q_{11} & \cdots & q_{1 m} \\
\vdots & \ddots & \vdots \\
q_{m 1} & \cdots & q_{m m}
\end{array}\right)_{m \times m}
$$

Generally, an m-though order square matrix is composed of h-step transition probability $q_{i j}(h)(i, j=1,2, \ldots, m)$ :

$$
q(m)=\left(q_{i j}(m)\right)_{m \times m}=\left(\begin{array}{ccc}
q_{11}(h) & \cdots & q_{1 m}(h) \\
\vdots & \ddots & \vdots \\
q_{m 1}(h) & \cdots & q_{m m}(h)
\end{array}\right)_{m \times m}
$$

Suppose $q=\left(q_{i j}\right)_{m \times m}$ and $q(h)=\left(q_{i j}(h)\right)_{m \times m}$ are the onestep and h-step transition probability matrices of Markov chain, respectively; then, the h-step transition probability matrix is exactly equal to one-step transition. The $h$ is the power of the probability matrix.

3.1.2. Markov Model Prediction Steps. The basic theories and methods of Markov chain can be used to analyze and study the flow of human resources in family businesses and to predict the structure of human resources in family businesses in the future. Specific steps are as follows.

The first step is to conduct a human resources survey of the family business. At the beginning of the research period, the number of $i$-level human resources has been initially distributed:

$$
q^{o}=\left(q_{1}^{0}, q_{2}^{0}, \cdots, q_{m}^{0}\right)
$$

Assuming that the number of human resources at $i$ levels at the beginning of the study period is $m_{1}, m_{2}, \ldots, m_{\mathrm{i}}$, then

$$
q_{i j}=\frac{m_{i}}{\sum m_{i}}
$$

The second step is to obtain the transfer frequency matrix according to the recent (2-3 years) human resource flow of the family business at $m$ levels and then obtain the transfer frequency matrix $q$. Suppose that among the current with level personnel, there will be $m_{i j}$ individuals in the position $j(j=1,2, \ldots, m ; i=1,2, \ldots, m)$ in the next employment period. Then, the transfer frequency matrix is $M=\left(m_{i j}\right)_{m \times m}$. By removing the row elements of the matrix $M$ $(i=1,2, \ldots, m)$, the transition matrix $q=\left(q_{i j}\right)_{m \times m}$ is obtained, where [24]

$$
q_{i j}=\frac{m_{i}}{\sum m_{i}},(j=1,2, \cdots, m ; j=1,2, \cdots, m) .
$$



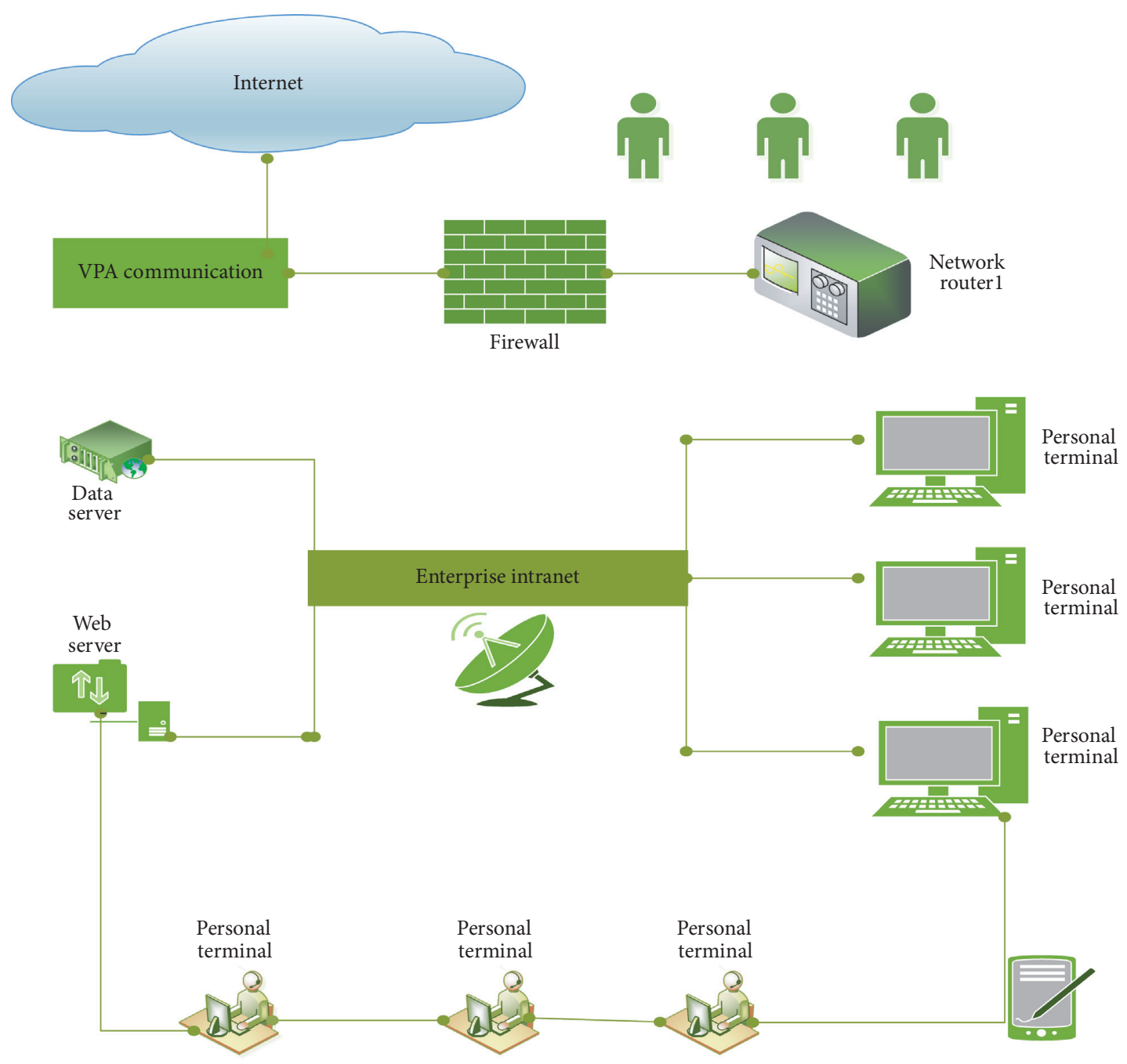

Figure 3: Network topology diagram.

The third step is to predict the distribution rate of personnel for the h-though appointment period in the future. Calculate the product of the initial distribution $q^{0}$ and the h-step transition matrix $q(h)$ to obtain the absolute distribution of the h-though appointment period in the future, that is, the distribution rate of the $h$-though appointment period:

$$
q^{h}=\left(q_{1}^{h}, q_{2}^{h}, \cdots, q_{m}^{h}\right)=\left(q_{1}^{0}, q_{2}^{0}, \cdots, q_{m}^{0}\right) q(h)
$$

The fourth step is to predict the distribution rate of human resources of $\mathrm{m}$-level family businesses in a balanced state. If the transition matrix $q$ is a normal matrix, then $q$ has a unique fixed point $u=\left(u_{1}, u_{2}, \ldots, u_{\mathrm{m}}\right)$, so when the development of the enterprise reaches a stable equilibrium state, the personnel occupancy rates of various levels will be $u_{1}$, $u_{2}, \ldots, u_{m}$.

3.2. Realization of Job Allocation in the Human Resources System of Family Business. Suppose the department distribution and personnel structure of family business A in 2020, as shown in Figures 4 and 5.
From the above chart, it can be seen that the number of personnel structures of the family business in 2020 is 30 high-level employees, 120 middle-level employees, 401 basic-level employees, and 49 retired personnel. According to the rectangular transfer model and corporate historical data, the transfer of various types of personnel the probability matrix is

$$
\begin{aligned}
q(m)=\left(q_{i j}(m)\right)_{m \times m} & =\left[\begin{array}{cccc}
q_{11}(h) & q_{12}(h) & \cdots & q_{1 m}(h) \\
q_{21}(h) & q_{22}(h) & \cdots & q_{2 m}(h) \\
\cdots & & & \\
q_{m 1}(h) & q_{m 2}(h) & \cdots & q_{m m}(h)
\end{array}\right], \\
q & =\left[\begin{array}{cccc}
0.75 & 0.15 & 0 & 0.1 \\
0.07 & 0.71 & 0.1 & 0.12 \\
0 & 0 & 0.82 & 0.18 \\
0 & 0 & 0 & 1
\end{array}\right] .
\end{aligned}
$$

Assuming that the current staff structure is $m^{0}=(30,120$, $401,49)$, the staff structure after one year is 


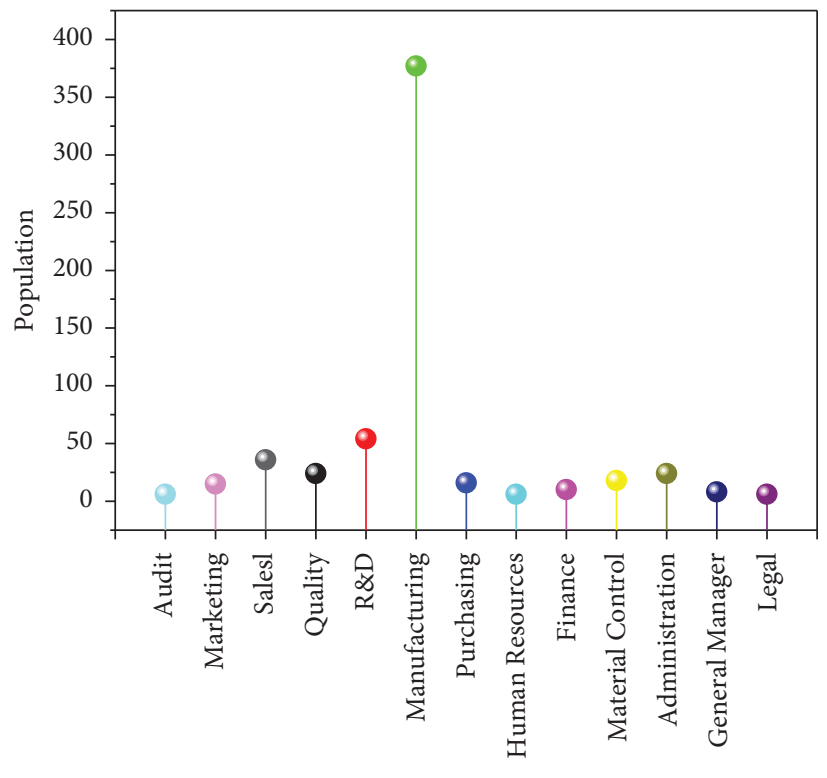

Population

Figure 4: Distribution map of enterprise department staff.
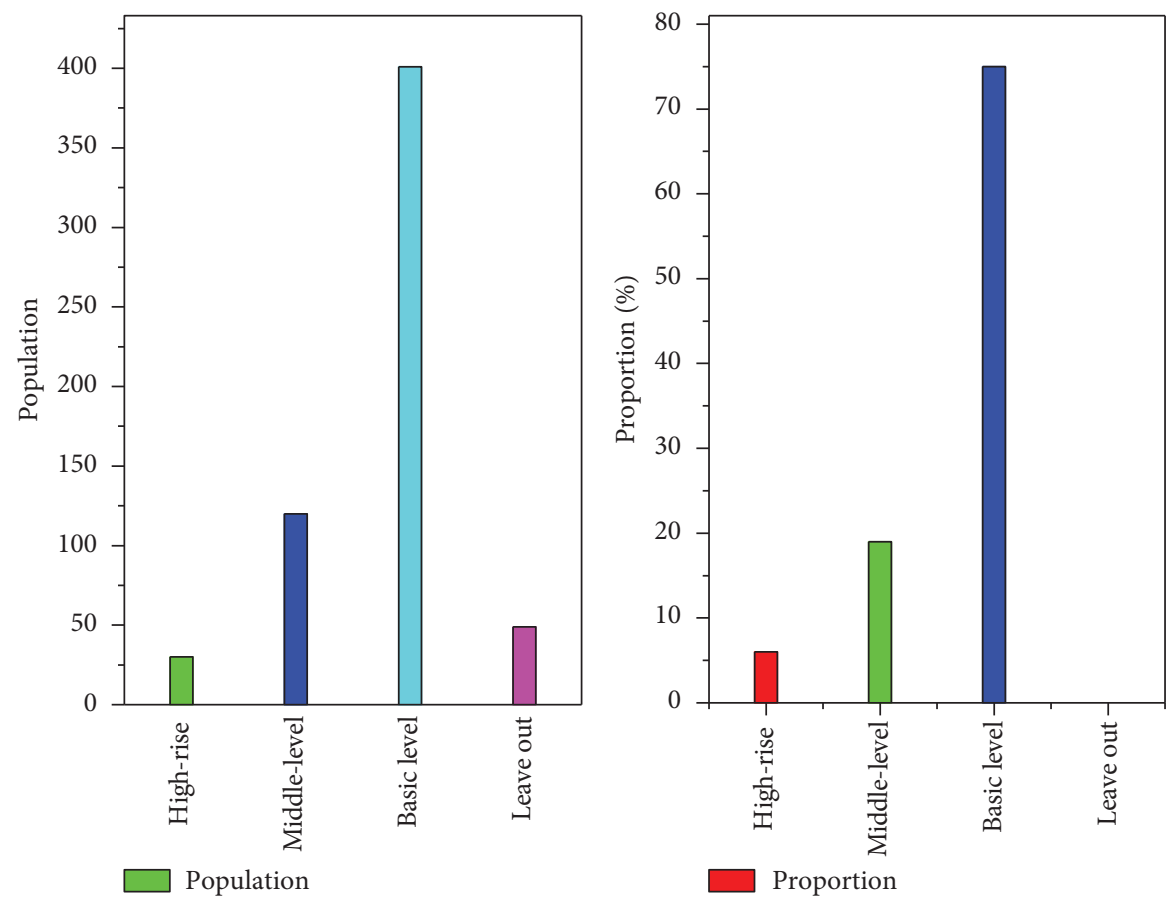

FIGURE 5: Enterprise hierarchy diagram.

$$
m^{1}=m^{0} * q=(30,95,412,63)
$$

that is, in the first year, there were 30 people at the top level, 95 people at the middle level, 421 people at the grassroots level, and 63 retired personnel. According to calculations, the staff structure after two years is as follows:

$$
m^{2}=m^{1} * q=(29,76,390,105)
$$

that is, in the second year, there were 29 high-level employees, 76 middle-level employees, 390 grassroots employees, and 105 retired personnel. After three years, the staff structure will be

$$
m^{3}=m^{2} * q=(27,61,372,130)
$$

According to calculations, three years later, the personnel structure of family business A is 27 high-level 
employees, 61 middle-level employees, 512 basic-level employees, and 130 retired employees.

\subsection{Analysis of the Result of Optimizing and Predicting Family} Business Human Resources. Based on the Markov model, use transition probability matrix analysis to predict the distribution and flow of family business $\mathrm{A}$ in three years, as shown in Figure 6:

According to the analysis of the graph, according to Markov model predictions, from 2020 to 2023, high-level, middle-level, and grassroots personnel will show a gradual downward trend, and the retired personnel will show an upward trend. With the development of informatization and the improvement of the management level, the demand for personnel of enterprises will decrease year by year. According to the supply of various human resources, the principle that the number of annual new personnel plan is lower than the expected annual reduction of personnel should be highlighted. Personnel matching and supplydemand balance are two key points; plan ahead and reasonably determine the quality and quantity of various job requirements, optimize the human resource structure, improve the company's resilience, and better adapt to the new situation facing enterprise development in the new era. Since Markov model predictions have certain errors, the data must be further verified to improve accuracy.

3.4. Competency Analysis of Human Resources Posts in Family Enterprises. The competency content can be obtained from the professional knowledge and skill level and performance of the position. With reference to the cultural level of various positions of the company, the performance is calculated through the model, and the analysis is combined with the requirements of the competence index. The statistical results are shown in Figure 7.

It can be seen from the figure that the family business has different requirements for education, competence, and performance due to different positions and responsibilities. The competency model excludes factors such as personality, attitudes, and values, by studying the relationship between competency and performance. For example, front-line employees have higher requirements for competency, but at the same time, lower requirements for education and performance. On the contrary, the branch manager, who is the main person in charge of the company, needs to formulate branch company indicators, requires a higher level of education and a lot of experience, and his own competence also rises with the growth of working years. Therefore, competency requirements are relatively low, but they need to lead employees to create value. Therefore, the performance appraisal index is the highest. There is a significant reference basis when formulating the human resource allocation plan to achieve the purpose of matching people and positions and to improve the efficiency of enterprise human resource management. Employees with high competency indicators and outstanding performance are outstanding employees. The company should focus on and train them through their promotion applications, give appropriate rewards, and be

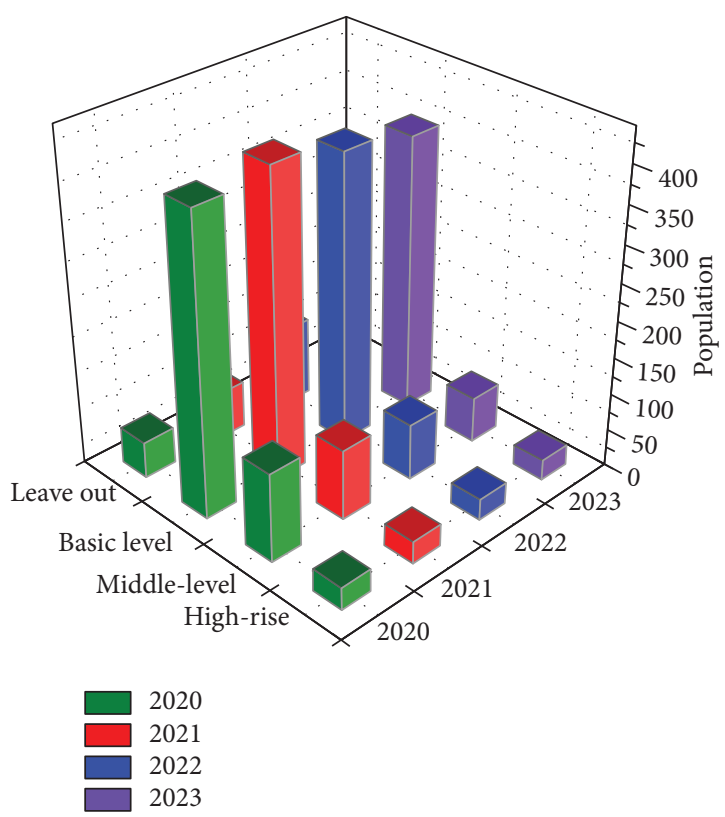

FIGURE 6: Distribution map of personnel structure from 2020 to 2023.

included in the company's talent echelon. Employees with high competency indicators and performance at the downstream level indicate that they are highly compliant with the company's instructions and content, but their personal characteristics are not prominent. The company should assist in analyzing the reasons for low performance, and provide guidance or arrange other positions suitable for this employee. Employees with low competency indicators and high performance indicate that their personal business level is high, but their teamwork ability is low, and they need competency training to work hard towards the double-high staff echelon. For employees with low competency indicators and low performance indicators, the company will give them an opportunity to enter the training. If they fail to meet the company's requirements after the training, the company will persuade them to leave. Through the above classification, it is conducive to help employees to classify target-oriented training to match people and positions, and the company's human resource allocation plan is further optimized. In practical applications, the competency model must comprehensively consider factors such as performance, skills, motivation, and personality and conduct a comprehensive summary analysis of multiple aspects.

3.5. Analysis of Accuracy of Markov Model Prediction Results. Through the use of multiple models to predict the distribution of job personnel in family businesses, test data in various situations, and on this basis, appropriately increase and decrease the sample's personnel change information and calculate the accuracy of the forecast. The relative error and accuracy rate statistics of the prediction results are shown in Figure 8.

By comparing with other model predictions, it is concluded that the Markov model algorithm has the highest 

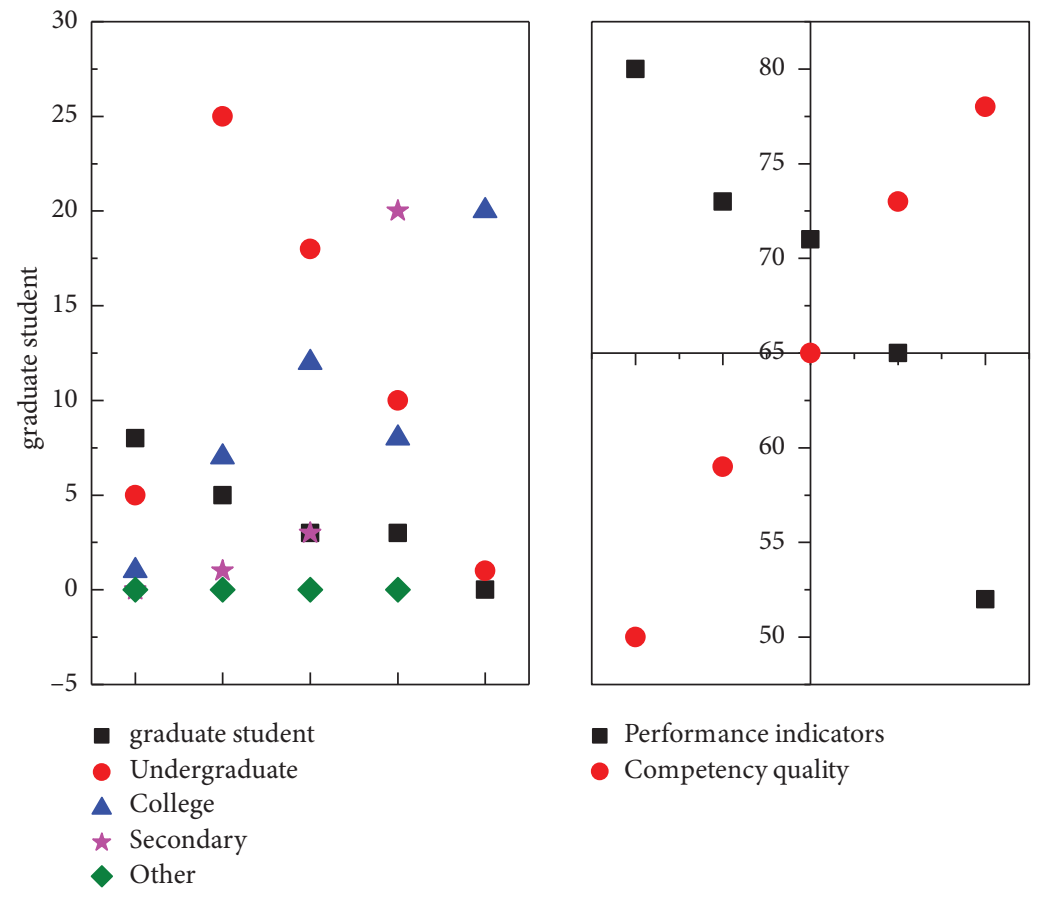

FIgURE 7: Analysis chart of job performance and competency quality.
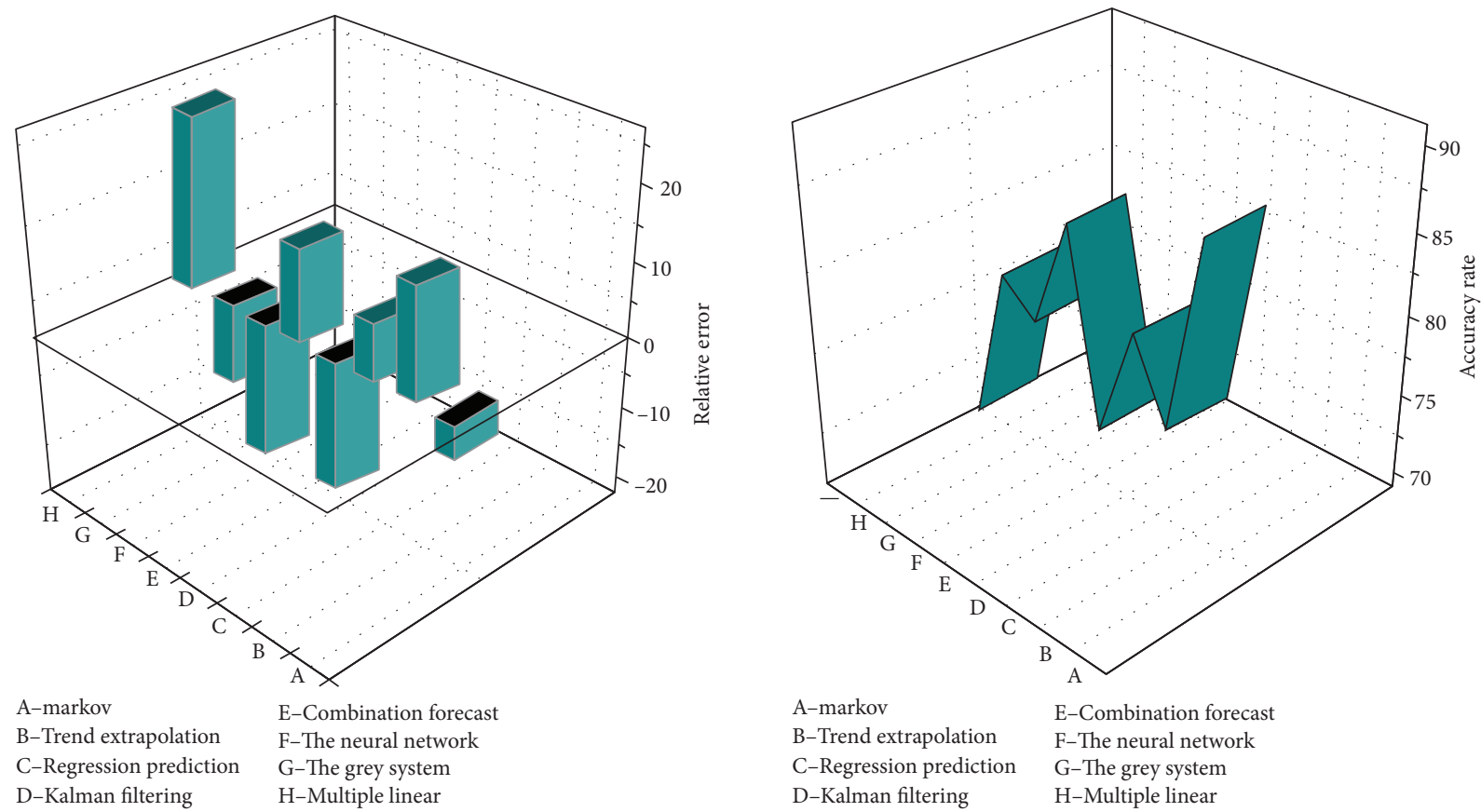

FIGURE 8: Forecast preparation rate and relative error statistics chart.

accuracy rate and the lowest relative error rate. Judging from the results, this method can predict most of the tests, but there are also certain errors and defects, making a small part of the prediction results inconsistent with the actual. By checking the real data of the test set, due to the uncertainty of various influencing factors, the model parameters cannot be fully trained, so the forecast results are slightly biased, but it does not affect the optimal allocation of human resources. The accuracy of the forecast results makes the recruitment of family businesses predictable, clarify the source and quantity of the supply of various types of personnel in the company, accurately formulate the talent needs of each job position, and plan the recruitment of talents in the society. Increase the recruitment ratio of grassroots staff, combine the actual 
nature of grassroots posts and salary conditions, and make full use of human resource management market information release.

In actual work in the future, we need to establish a more intelligent human resource management system based on the Markov model. In the future, more in-depth and accurate predictive analysis will be carried out in terms of personnel flow, so as to provide more analysis and decisionmaking basis for future family business human resources work.

\section{Data Availability}

The data used to support the findings of this study are available from the corresponding author upon request.

\section{Conflicts of Interest}

The author declares that there are no conflicts of interest.

\section{References}

[1] L. Gomez-Mejia, R. Basco, A. C. Gonzalez, and C. G. Muller, "Family business and local development in Iberoamerica," Cross Cultural and Strategic Management, vol. 27, no. 2, pp. 121-136, 2020.

[2] I. Miroshnychenko, A. De Massis, D. Miller, and R. Barontini, "Family business growth around the world," Entrepreneurship: Theory and Practice, vol. 45, no. 4, pp. 682-708, 2021.

[3] S. B. Rau, J. H. Astrachan, K. X. Smyrnios, and K. X. Smyrnios, "The F-PEC revisited: from the family business definition dilemma to foundation of theory," Family Business Review, vol. 31, no. 2, pp. 200-213, 2018.

[4] S. Bouajaja and N. Dridi, "A survey on human resource allocation problem and its applications," Operational Research, vol. 17, no. 2, pp. 339-369, 2017.

[5] K. B. Aviso, C. D. Cayamanda, A. P. Mayol, and K. D. S. Yu, "Optimizing human resource allocation in organizations during crisis conditions: a P-graph approach," Process Integration and Optimization for Sustainability, vol. 1, no. 1, pp. 59-68, 2017.

[6] S. L. DeRuiter, R. Langrock, and T. Skirbutas, "A multivariate mixed hidden Markov model for blue whale behaviour and responses to sound exposure," Annals of Applied Statistics, vol. 11, no. 1, pp. 362-392, 2017.

[7] M. Tadayon and G. J. Pottie, "Predicting student performance in an educational game using a hidden Markov model," IEEE Transactions on Education, vol. 63, no. 4, pp. 299-304, 2020.

[8] J. V. Monaco and C. C. Tappert, "The partially observable hidden Markov model and its application to keystroke dynamics," Pattern Recognition, vol. 76, pp. 449-462, 2018.

[9] P. Ballesteros-Pérez, F. T. T. Phua, and D. Mora-Melià, "Human resource allocation to multiple projects based on members' expertise, group heterogeneity, and social cohesion," Journal of Construction Engineering and Management, vol. 145, no. 2, Article ID 04018134, 2019.

[10] U. Ayesta, M. Erausquin, E. Ferreira, and P. Jacko, "Optimal dynamic resource allocation to prevent defaults," Operations Research Letters, vol. 44, no. 4, pp. 451-456, 2016.

[11] D. Witteveen and P. Attewell, "The college completion puzzle: a hidden Markov model approach," Research in Higher Education, vol. 58, no. 4, pp. 449-467, 2017.
[12] J. Duan, F. Jiao, Q. Zhang, and Z. Lin, "Predicting urban medical services demand in China: an improved grey Markov chain model by taylor approximation," International Journal of Environmental Research and Public Health, vol. 14, no. 8, p. 883, 2017.

[13] A. F. Karikari, P. A. Boateng, and E. O. N. D. Ocansey, "The role of human resource information system in the process of manpower activities," American Journal of Industrial and Business Management, vol. 5, no. 6, p. 424, 2015.

[14] G. T. H. Vu, "A critical review of human resource competency model: evolvement in required competencies for human," Journal of Economics, Business and Management, vol. 5, no. 12 , pp. $357-365,2017$.

[15] C. C. Crispin, A. Vasumathi, and R. Subashini, "The role of strategic human resource management (SHRM) impacting employee's performance through perceived organisational support in a manpower agency of international airlines at Chennai International Airport, Tamil Nadu, India - an empirical study," International Journal of Services and Operations Management, vol. 23, no. 2, pp. 217-234, 2016.

[16] S. Rafiei, R. Mohebbifar, F. Hashemi, M. R Ezzatabadi, and F Farzianpour, "Approaches in health human resource forecasting: a roadmap for improvement," Electronic Physician, vol. 8, no. 9, pp. 2911-2917, 2016.

[17] A. Vaish and S. Sengupta, "Manpower retention and cost control strategies in Indian service sector-A human resource perspective," Australian Journal of Accounting, Economics and Finance, vol. 3, no. 2, pp. 76-83, 2017.

[18] L. Wang and G. Liu, "The manpower planning model for optimizing human resource based on flow cost," Journal of Applied Science and Engineering Innovation, vol. 3, no. 6, pp. 237-241, 2016.

[19] M. R. Luddin and S. Thomas, "Human resource architecture transformation case study in construction company," IJHCM (International Journal of Human Capital Management), vol. 3, no. 2, pp. 27-41, 2019.

[20] J. R. Methot, E. H. Rosado-Solomon, and D. G. Allen, "The network architecture of human captial: a relational identity perspective," Academy of Management Review, vol. 43, no. 4, pp. 723-748, 2018.

[21] G. K. Stahl, C. J. Brewster, D. G. Collings, and A. Hajro, "Enhancing the role of human resource management in corporate sustainability and social responsibility: a multistakeholder, multidimensional approach to HRM," Human Resource Management Review, vol. 30, no. 3, Article ID 100708, 2020.

[22] M. Y. Morais and H. Akbar, "The design of application architecture of the institute of business based on enterprise architecture planning," IJITEE (International Journal of Information Technology and Electrical Engineering), vol. 2, no. 2, pp. 31-38, 2018.

[23] C. Boon, D. N. Den Hartog, and D. P. Lepak, "A systematic review of human resource management systems and their measurement," Journal of Management, vol. 45, no. 6, pp. 2498-2537, 2019.

[24] R. Hewett, A. Shantz, J. Mundy, and K. Alfes, "Attribution theories in human resource management research: a review and research agenda," International Journal of Human Resource Management, vol. 29, no. 1, pp. 87-126, 2018. 